\title{
Lunar Regolith Characterization for Simulant Design and Evaluation Using Figure of Merit Algorithms
}

\author{
Christian M. Schrader" \\ BAE Systems, Marshall Space Fhigh Center, Huntswlle AL 35805 \\ Douglas L. Rickman ${ }^{2}$, Carole A. Molemore, and John C. Fikes \\ NASA, Marshall Space Flight Center, Huntsille AL 35812 \\ Douglas B. Stoeser ${ }^{5}$ \\ United States Geological Survey, Denver CO 80225 \\ and \\ Susan J. Wentworth ${ }^{6}$ and David S. Mckay ${ }^{7}$ \\ Johnson Space Center, Clear Lake TX 77058
}

\begin{abstract}
NASA's Marshall Space Flight Center (MSFC), in conjunction with the United States Geological Survey (USGS) and aided by personnel from the Astromaterials Research and Exploration Science group at Johnson Space Center (ARES-JSC), is implementing a new data acquisition strategy to support the development and evaluation of lunar regolith simulants. The first analyses of Junar regolith samples by the simulant group were carried out in early 2008 on samples from Apollo 16 core $64001 / 64002$. The results of these analyses are combined with data compiled from the literature to generate a reference composition and particle size distribution (PSD) for lunar lighlands regolith. In this paper we present the specifics of particle type composition and PSD for this reference composition. Furthermore, we use Figure of Merit (FoM) routines to measure the characteristics of a number of lunar regolith simulants against this reference composition. The lunar highlands regolith reference composition and the FoM results are presented to guide simulant producers and simulant users in their research and development processes.
\end{abstract}

\section{Introduction}

The HE current lunar architecture calls for the establishment of a permanently manned lunar outpost by 2020 . To support this effort, the lunar engineering community is developing and testing technologies for $n$ Sin Resource Utilization (ISRU), excavation and drilling, and mitigation of hazards to machinery and human health. The scarcity of Apolto samples for testing purposes necessitates the use of lunar regolith simulants as proxy materials. The development and evaluation of simulants requires a highly detailed understanding of regolith particle characteristics. The Marshall Space Flight Center (MSFC)-led group has developed Figure of Merit (FoM) algorithms and compiled a theoretical reference hightands regolith material against which to quantitatively compare simulants.

\footnotetext{
Geologist, National Space Science Techology Center, 320 Sparkman Drive.

Project Scientist, Earth Science Office NP61.

Project Manager/VP33.

Deputy Project Manager/VP33.

Sesearch Geologist, Central Region Mineral Resources Team, MS973 Box 25046 DFC.

Geologist, ERC/ESC Group, Mail Code JE23

'Senior Scientist, NASA
}

1 American Institute of Aeronautics and Astronautics 


\section{Figures of Merit}

The purpose of the Figure of Merit (FoM) is to quantiatively compare, for a defined parameter or set of parameters, a regolith simulant to a reference material, where the reference may be a regolith sample, a hypothetical regolith sample, or other batches or types of simulants ${ }^{1,2}$. Though FoM algorithms exist for particle type (modal) composition, particle size distribution (PSD), particle shape distribution, and density, we here compare materials only using the particle type composition and PSD algorithms.

The FoM is defined as a value between 0 and 1 . As the two materials become more similar the FoM approaches 1. Mathematically, the composition foM is the nomalized difference of the composition vectors of the two materials (reference and simulant) subtracted from unity. Normalization forces the difference of two composition vectors to lie between 0 and 1 , and subtraction from unity results in a Figtre-of-Merit of 1 for a perfect match to 0 for no match at all. The FoM for composition may be interpreted as the fraction of materiat that is the same in both materials!

Mathematically, the particle size FoM is the difference between the size relative frequency distributions, which are the derivatives of the size cumulative frequency distributions of the two materials, subtracted from unity. Again, a Figure-of-Merit of 1 is a perfect match and 0 is no match at all'.

\section{Apollo Regolith Reference Material}

NASA's current lunat architecture calls for initial outposts to be placed in the lunar polar regions, which are, to the best of our knowledge, mantled by highlands-type lunar regolith. Of the Apollo missions, only Apollo 16 visited a site located entirely in the lunar highlands, and so we use Apolo 16 regolith samples as the reference materials to guide simulant development and evaluation. Cores are our preferred sample types as they provide samples across a depth profile, and many proposed operations on the moon will involve excavation of lunar regolith to depths of tens of centimeters. As the lunar architecture expands or evolves, we can incorporate reference materials from other lunar locales like maria and the KREEP menriched Procellaritm terrane.

The reference material used here for Figure of Merit calculations is the integrated suite of subsamples from Apollo core $64001 / 64002$, which is a sample of lunar highlands regolith from Apollo 16 Station $4 \ldots$ the southeasternmost site on the flanks of Stone Mountain. We chose the $64001 / 64002$ core because it is a complete and intact core, it is deemed representative of Apollo 16 site regolith $^{3,4}$, and it has been well-studied ${ }^{3 \cdot 6}$.

\section{A. Reference Particle Type Composition}

All particle type composition data can be found in Table 1 - it includes the reference composition derived from fiterature $^{34}$ and analyses as described below as well as the simulants described in the next section.

l. Literature

We averaged modal particle type data from two studies of core $6400164002^{3,4}$ for the basis of the FoM lunar reference material: for sample $64001^{3}$, the lower $-30 \mathrm{~cm}$ of the core and from $64002^{4}$, the top $\sim 30 \mathrm{~cm}$ of the core. Each study examined six size fractions from 20 to $500 \mu \mathrm{m}$ of six subsamples of the core at $-5 \mathrm{~cm}$ interval. The authors use a consistent particle classification system ${ }^{7}$ and calculate a weighted average, by weight $\%$ of the size fractions, of the compositions of each subsample. We combined these subsample averages to a single mean particle type composition of the 20-500 $\mathrm{um}$ portion of the $64001 / 64002$ core.

This particle type classification ${ }^{7}$ has primarily been used with data generated by optical microscopy of very fine particles and thus some minerals are not classiffed to the level of specificity we desire. For instance, pyroxenes are not differentiated to clino or orthopyroxene, and all spinel minerals (chromite, spinel, and utvospinel), ilmenite, and sulfides are undifferentiated as "opaques".

More than $90 \%$ of the particles by weight of most lunar regolith samples are less than $500 \mu \mathrm{m}$ in diameter". An average of $-20 \mathrm{wt} \%$ of most regolith falls below $20 \mathrm{um}^{8}$, but modal data for this fraction are scarce. Therefore, we consider this $20-500 \mu m$ dataset to be the best available in the literature for our purposes.

2. Scaning electron microscopy (SEM) and energy dispersive Xray spectroscopy (LDS)

We generated modal data from QEMSCAN SEM-EDS microbeam analysis of Apollo 16 samples from drive core $64001 / 64002^{\text {s.2.2. }}$. The analyzed hnar samples were thin sections $64002,6019(5.0-8.0 \mathrm{~cm}$ deph) and $64001,6031(50.0-53.1 \mathrm{~cm}$ depth) and sieved grain mounts 64002,262 and 64001,374 from dephs corresponding to the thin sections, respectively. We analyzed four size fractions from each grain mount sample: $500-250 \mathrm{~km}, 150-90$ um, $75-45 \mu \mathrm{m}$, and $<20 \mu \mathrm{m}$ fractions. These data are not particle type modal data but rather total area modat $\%$ by phase, either as type of mineral or glass." The area modal\% is derived from focused bean analyses at stepped intervals. 
For the lunar reference composition, we use the ratios of certain mineral classes from these SEM/EDS data to augment our particle type modal data from the literature. For instance, when the literature data ${ }^{3,4}$ repont only "pyroxene", we subdivide these into clinopyroxene and orthopyroxene based on the QEMSCAN -generated ratio". Furthemore, we divide their "opaques" into ilmenite, Fe-sulfide, and spinels (not further differentiated).

3. Plagioclases composition

Plagioclase feldspar is the only mineral for which we currently evaluate chemical compositional variability in the FoM algorithm. We use the generally accepted composition of An95 for lunar highland regolith plagioclase. This means the plagioclase is 95 molar of the $\mathrm{CaAl}_{2} \mathrm{Si}_{2} \mathrm{O}_{3}$ (anorthite) end member and only 5 molar of the $\mathrm{NaAlSi}_{3} \mathrm{O}_{3}$ (abite) end-member. We include plagioclase composition in the FoM because:

- it is the most abundant mineral in the highlands regolith;

- it is the only mineral for which we have reasonable compositional data in both the regolth and the simulants; and

- Itnar highlands plagioclase is more calcic than almost any terrestrial plagioclase, and we view closeness to lunar plagioclase composition as a significant marker of simulant fidelity.

\section{B. Reference Particle Size Distribution}

The particle size distribution data (PSD) for $64001 / 64002$ is taken from the literature. It is an average of 12 subsamples by weight\% of each size fraction. Figure 1 shows the average Apollo $1664001 / 64002$ PSD. All data is from dry sieving.

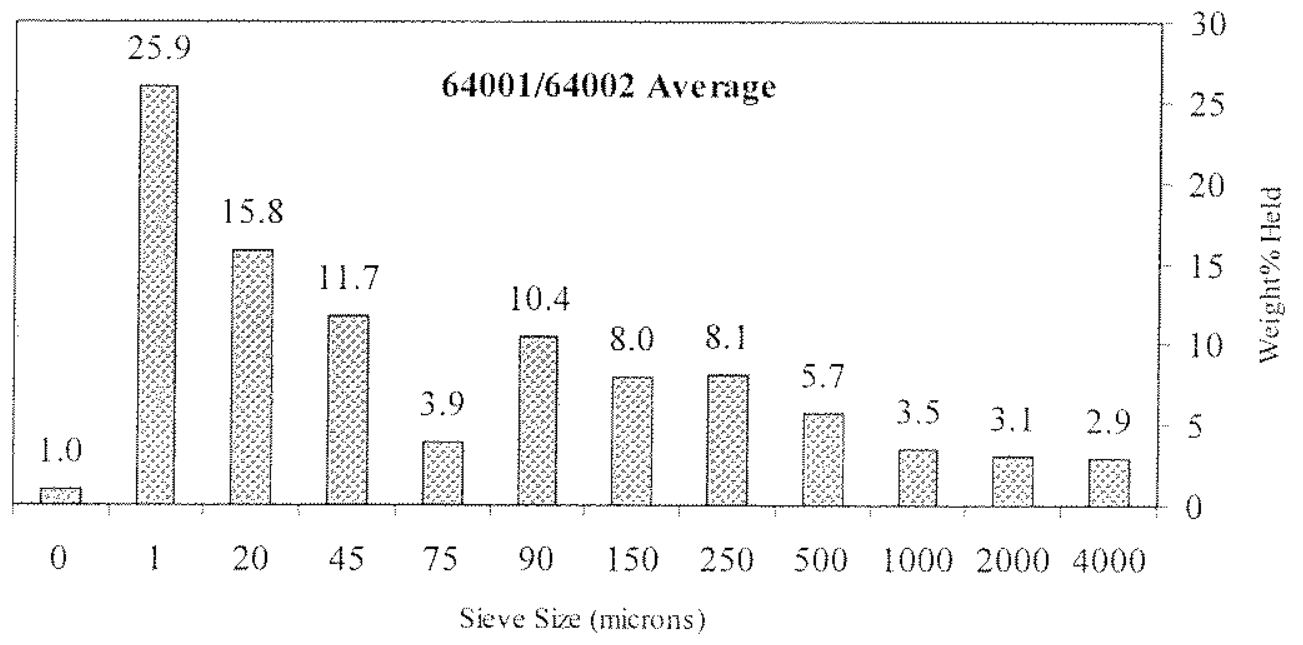

Figure 1. Particle size distribution data for Apollo 16 core 64001/64002. Data from Graf, 1993.

\section{Simulant Compositions and Particle Size Distributions}

As part of the ongoing effort to evaluate and guide lunar regolith simulant development, we have gathered data on existing and previously used simulants so as to compare them to our Apollo Reference material. We have analyzed simulants of varying types and sources. These include: JSC-1, JSC-1A, and JSC-1AF (fines) are mare simulants approximating A pollo 14 regolth ${ }^{3,2}$; Japan's JS-1 analyzed here is a mare simulant also approximating Apollo 14 regolith, but other variations of FJS-1 included materials added to simulate Apollo 11 and Apollo 16 regolith ${ }^{1 / 4}$ MLS-1 (Minnesota Lunar Simulant) as tested here (processed in a plasma stream to generate a glass component) is a high-Ti mare simulant that approximates Apollo 11 high-Ti mare regolith; Canada's OB-I is a 
highand simulant intended for mechanicalphysical simulation of regolith; and the NASAUSGS medium-and dustsized NU-LHT-1M, NU-LHT-2M, and NU-LHT-ID are highland simulants intended for general purpose.

\section{A. Simulant Composition}

\section{SEM/EDS aralyses}

All of the simulants are considerably less texturally complex than the analyzed lunar regolith and so we were able to obtain consistent particle type analyses by QEMSCAN ${ }^{2}$ SEM/EDS analysis. The software used for textural analysis and particle identification is the iDiscover 4.2 package developed by Intellection, Ltd. and incorporated into QEMSCAN technology. The user is able to differentate and classify basal fragments in some simulants grouped as "lithic fragments" in our foM analysis), and the pseudo-agglutinate fragments (grouped as "agglutinates" in our FoM analysis) in the NU-LHT series simulants.

2. Plagioclase composition

Plagioclase compositions in the simulants, either from published or presented analyses ${ }^{17}$ or from best estimates based on feedstocks ${ }^{2}$, are included in the composition foM analysis.

Table 1. Particle type modal data, and plagioclase molar\% Anorthite, for the lunar reference material and regolith simulants. See text for data sources.

\begin{tabular}{|c|c|c|c|c|c|c|c|c|c|}
\hline & $\begin{array}{l}64001 / \\
64002\end{array}$ & $\begin{array}{c}\mathrm{NU} \\
\mathrm{IHT}- \\
1 \mathrm{M}\end{array}$ & $\begin{array}{l}\mathrm{NU}- \\
\mathrm{LHT} \\
-2 \mathrm{Y} \\
\end{array}$ & OB-1 & $\mathrm{JSC}-1$ & $\begin{array}{c}\text { ISC- } \\
1 A\end{array}$ & $\begin{array}{l}\mathrm{JSC} \\
\mathrm{AFF}\end{array}$ & FIS-1 & MLS-1 \\
\hline Lithic Fragments & 31.11 & 0.00 & 0.00 & 0.00 & 9092 & 90.92 & 91.93 & 80.18 & 52.28 \\
\hline Glass & 8.88 & 22.37 & 7.17 & 52.63 & 0.00 & 0.00 & 0.00 & 0.53 & 36.57 \\
\hline Agglutinates & 32.51 & 29.02 & 23.49 & 0.00 & 0.00 & 0.00 & 0.00 & 0.00 & 0.00 \\
\hline Plagioclase & 23.32 & 38.78 & 54.89 & 4393 & 1.54 & 1.54 & 3.39 & 14.11 & 2.60 \\
\hline (Plag $A n^{(3 / i s)}$ & 95 & 80 & 80 & 75 & 68 & 70 & 70 & $50 ?$ & 47 \\
\hline Olivine & 0.00 & 2.88 & 9.51 & 0.04 & 5.63 & 5.63 & 4.13 & 1.13 & 0.01 \\
\hline Clinopyroxene & $0.6 \$$ & 2.04 & 3.98 & 0.07 & 1.33 & 1.33 & 0.42 & 1.20 & 2.21 \\
\hline Orthopyroxene & 3.24 & 4.37 & 0.20 & 0.00 & 0.01 & 0.01 & 0.01 & 0.04 & 0.03 \\
\hline Spinel minctals & 0.03 & 0.05 & 0.01 & 0.19 & 0.00 & 0.04 & 0.02 & 0.05 & 0.03 \\
\hline Fe+sulfide & 0.01 & 0.00 & 0.04 & 0.00 & & 0.60 & 0.00 & 0.00 & 0.00 \\
\hline Camphospates & 0.12 & 0.00 & 0.43 & 0.00 & 0.00 & 0.00 & 0.00 & 0.00 & 0.00 \\
\hline llmenite & 0.13 & 0.33 & 0.19 & 0.00 & 0.00 & 0.08 & 000 & 0.15 & 1.67 \\
\hline Naive Iron & 0,01 & 0.00 & 0.00 & 0.00 & & 0.00 & 0,00 & 0,00 & 0.00 \\
\hline Other (sim. only) & & 0.16 & 0.07 & 3.12 & & 0.46 & 0.09 & 2.62 & 5.21 \\
\hline Total & 100 & 100 & 100 & 100 & 100 & 100 & 100 & 100 & 100 \\
\hline
\end{tabular}

\section{B. Simulant Particle Size Distribution}

We used multiple sources of simulant size distribution data, and in most cases multiple data sources are represented per simulant.

1. Dry Sieving

Some data are from dry sieving methods and reported by weight $\%$. The data for $O B+1$ comes from Trow Analytical, Ltd. The analyses for JSC-1A and NU-LHT-1M were performed in the lab of Dr. Susan Batiste at the University of Colorado Boulder.

2. SEM and image processing

We have size data from QEMSCAN SEMEOS analysis, reported by weight\%, for all simulants except for NULHT-1D. It should be said that grain mounts used for SEM imaging are polished and thus provide a sectioned sample, and that most particles will not be sectioned at their plane of greatest diameter equivalent. For this reason such results are sometimes referred to as an SSD (sectional size dismibution) rather than a PSD. The high number of particles counted partialy offsets this effect, but there will aways be a slight bias towards finer partictes in an SSD. 
This can be partially compensated for by stereological techniques and we are pursuing this approach. For now, we cattion the users to take this into account, but also remind them that all simulants were measured by this method and thus any problems will be consistent across that portion of the dataset.

\section{Liquid dispersion and laser diffractometry}

We have data for NU-LHT-IM, -2M, and -1D, and ISC-1A from liquid dispersed laser diffractometry. Susan Batiste at the University of Colorado Boulder measured NU-LHT-IM and SSC-1A, while the Bureau of Mines analyzed NU-LHT-2M and $-1 \mathrm{D}$.

These data are presented as volume \% rather than as weight \%. If the particle composition distribution were consistent across the size fractions then the data would be equivalent, but this is not true for lunar regolith and is likely not to be true for simulants. However, we judge it likely that the deviations in density across the size fractions are of small effect. We leave if to the user to evaluate these ratings until more data are gathered and analyses are presented. Again, the method is consistent for the four simulants measured and thus is of comparative value.

This analytical method yields more bins of data (smaller size fractions) than the FoM software allows. We have summed the bins to best match the bins in the literature lunar data".

\section{Results of Figure of Merit Analyses}

\section{A. Particle Type Composition Results}

All composition FoMs were run using a revised form of Figure of Merit Version 1 software not yet released. Table 2 presents the Figure of Merit composition results for all simulants tested against our $64001 / 64002$ lunar reference material.

Table 2. Results of Figure of Merit composition analysis. Figure of Merit $V$.

1, Rev. I algorithm used with lunar reference material $64001 / 64002$.

\begin{tabular}{c|c}
\hline simulant & $\begin{array}{c}64001 / 64002 \\
\text { reference }\end{array}$ \\
\hline NU-LHT-1M & 0.65 \\
NU-LHT-2M & 0.55 \\
OB-1 & 0.28 \\
JSC-1 & 0.33 \\
JSC-1A & 0.35 \\
JSC-1AF & 0.43 \\
MLS-1 & 0.35 \\
\hline FJS-1 & 0.36 \\
\hline
\end{tabular}

\section{B. Particle Size Distribution Results}

The particle size Figures of Merit were run using the Figure of Merit Version 1 software. The results are shown in Table 3. The range of size bins for $64001 / 64002^{\circ}$ is broader than for any of the simulants. All simulant PSD's are compared to the entire 64001/64002 PSD and the results are shown in the first colum of Table 3 . Most of the simulant PSD's only extend to $-1 \mathrm{~mm}$. The second column of Table 3 shows comparisons of all simulants to the $4 \mathrm{~mm}$ fractions of $64001 / 64002$. These fractions were recalculated to sum to 100 weight $\%$. For the two simulants specifically intended to be dust simulants, another normalized subset of literature data was used for comparison, this time recalculating the $90 \mu \mathrm{m}$ fraction to sum to 100 weight $\%$. We show the results for this subset in column 3 of Table 3 .

It is a complex problem to consistently classify fragments of rock and breccia in lunar and terrestrial material. In lunar regolith, particles comprise a spectrum of varying glass content and fracture. For this reason, all rock fragments and breccias in the simulants are classified as lithic fragments and compared to the abundance of all rock and breccia fragments in the regolith. 
Table 3. Figure of Merit size results for all simulants against $64001 / 64002$ Itmar reference material. Simulant datasets were compared against the bulk average of $64001 / 64002$, the $<1 \mathrm{~mm}$ subset of the data and the $<90$ $1 \mathrm{~m}$ subset of the data; both reference subsets were recalculated to $100 \%$. Analytical method is in parentheses.

\begin{tabular}{|c|c|c|c|}
\hline & $\begin{array}{c}64001 / 2 \text { bulk } \\
\text { average }\end{array}$ & $\begin{array}{l}6400 / 2<1 \\
\text { mm average }\end{array}$ & $\begin{array}{c}64001 / 2 \text { average to } \\
90 \mathrm{~mm}\end{array}$ \\
\hline OB-1 (section image analysis) & 0.23 & 0.54 & \\
\hline NULLHT-IM (section image analysis) & 0.23 & 0.58 & \\
\hline NU-LHT-2M (section mage analysis) & 0.17 & 0.48 & \\
\hline ISC- 1 (section image analysis) & 0.22 & 0.53 & \\
\hline JSC-1A (section image analysis) & 0.25 & 0.56 & \\
\hline JSC-1AP (section image analysis) & 0.06 & 0.23 & 0.60 \\
\hline MLS-1 (section image analysis) & 0.20 & 0.29 & \\
\hline FIS-1 (section image analysis) & 0.26 & 0.45 & \\
\hline OB-1 (dry sieve) & 0.59 & & \\
\hline NU-LHT-1M (dry sieve) & 0.26 & 0.75 & \\
\hline ISC-IA (dry sieve) & 0.35 & 0.74 & \\
\hline NU-LHT-2M (laser diffactometry) & 0.29 & 0.82 & \\
\hline NU-LHT-1D (laser diffractometry) & & & 0.54 \\
\hline NU-LHT-1M (laser diffractometry) & 0.26 & 0.64 & \\
\hline JSC-1A (laser diffractometry) & 0.28 & 0.74 & \\
\hline
\end{tabular}

Agglutinates are a member of the particle spectrum including lithic and breccia fragments, but we interpret them to be sufficiently unique in their properties and abundance as to be worth differentiating. Furthermore, their characteristics as irregularly shaped, often vesicular particles composed of minerals in a glass matrix makes it possible for the iDiscover software user to distinguish them based on results from the automated beam technology.

Because the lunar regolith reference $64001 / 64002$ is composed of -32 modal $\%$ agglutinates and 31 modal\% lithic fragments, simulants that do not approximate these abundances will score a low composition FoM score. They may still be appropriate simulants for many purposes, by virue of their chemistry, shape, or size distribution. Conversely, a simulant with appropriate abundances of these particles may be inappropriate for some uses.

\section{Conclusion}

These results are discussed in further detail in the Lunar Regolith Simulant User's Guide released by the Marshall Space Flight Center simulant project group. Further data on lunar highlands composition and PSD is still being gathered and compiled. We encourage users to contact the atthors at Marshall Space Flight Center for advisement as to simulant use. We predict that the Lunar Regolith Sinulant User's Gude will be updated at least annually, but new information is available constantly. These evaltations are ongoing, as is Figure of Merit development. Most importantly, simulant development is continuing.

\section{Acknowledgments}

The authors would like to thank the scientists of the Astromaterials Research and Exploration Science (ARES) group at Johnson Space Center, particularly Chuck Meyer and Dan Garrison for their expertise on lunar matters and their aid in finding and assessing data in the literature.

\section{References}

Rickman, D., Hoelzer, H., and Fourroux, K., "Lumar Figures of Merit", Lunar and Dust Regolth Simuknt Workshop, Hunisville, AL, 200 ?.

"Schrader, CM., Rickman, D., Stoeser, D., and Hoetzer, H., "Constraining Particle Variation in Lmar Regolith for Simulant Design", ALA SPACE 2008 Proceedings, San Diego CA, 2008. 
"Houck, K.J., "Modal Petrology of Six Soils from Apollo 16 Double Drive Tube 64002", Procedings of the 13 th Lunar and Planetary Science Conterence, Part 1, Joumat of Geophysical Research, Vol. 87, Supplement, 1982b, pp. A210-A220.

"Basu, A. and Mckay, D.S., "Petrologic Protile of Apollo 16 laegolith at Staton a", Proceedings of the 15 th Luma and Planetary Science Conlerence, Part 1, Journal of Geophysical Research, Vol. 89, Supplement, 1984, pp. C133-C142.

${ }^{5}$ Korotev, R.L." "Comparative Geochemistry of Apollo 16 Surface Solls and Samples from Cores 64002 and 60002 through $60007 \%$, Procedings of the 13 th Lunar and Planetary Science Conference, Part I, Joumal of Geoplysical Research, Vol.. 87, Supplement, 1982, pp. A269-A278.

"Korotev, R.L., Moris, R.V., and Later, H.V., J., "Stratigraphy and Geochemistry of the Stone Mountain Core (6400/2)". Procedings of the 15 h Lunar and Planetary Science Conference, Part 1, Journal of Geophysical Research, Vol. 89 , Supplement. $1984, \mathrm{pp} . \mathrm{Cl} 143 \mathrm{Cl} 60$.

Bxsu, A, and Mckay, D.S., "Classification of Lunar Highand's Submillimeler Particles", in Workhop On Apollo 16, edited by O.B. James and F. Hör. L.PI Technica Report 81-01, Lunar and Planetary Institute, Houston, 1981, pp. 36-39.

"Graf, I.C. "Lunar Orain Size Catalog", NASA Reference Publication 1265, 464 p.

"Schrader, C.M., Rickman, D. Stoeser, D., Wentworth, S.J., Botha, P.W.S.K., Butcher, A.B., Horsch, H., Bendicus, A., Gotlieb, P., and Mckay, D.S., "Analysis of Lunar Highland Regolith Samples from Apollo 16 Drive Core $64001 / 2$ and Lumat Regolith Simulants - An Expanding Comparative Database", Geological Society of Amerixa Amual Meeting, Houston TX, 2008 , abstract $345+13$.

"Rickman, D., Wentworth, S.J., Schrader, C.M., Stoeser, D., Botha, P.W.S.K., Butcher, A.B., Horsch, H., Benedictus, A., Goulieb, P., and McKay, D.S. "New Insight into the Composition and Texture of Lmar Regolith Using Ultratast Automated Electron Beam Analysis", Geological Society of America Anmual Meeting, Houston TX, 2008 , abstact $345-2$.

"Boha, P.W.S.K. Butcher, A.B., Horsch, Rickman, D., Wentworth, S.l. Sohrader, C.M., Stoeser, D., Benedictus, A., Gotlieb, P. and McKay, D.S. "Ultrafast Phase Mapping of Thin-Sections from an Apollo 16 Drive Tube - a New Vistalization of tumar Regolith". Geological Society of America Annual Meeting, Houston TX, 2008, abstract 345w3.

: Schrader, C.S., Rickman, R., Mclemore, C., Fikes, J., Wilson, S., Stoeser, D., Butcher, A., and Botha, P., "Extant and Exinct Lmat Regohth Stmulents: Modat Analyses of NU-LHT-IM and -2M, OB-1, ISC-I, ISC-IA and - IAF, FIS-I, and MLSI", Panetary Mining and Science Symposium, Montreal, 2008.

${ }^{13}$ Heiken, G., Vamiman, D., and French, B.M., Lunar Sourcebook. A User's Guide to the Moon, Cambridge University Press, Cambridge [England, New York, 1991.

${ }^{14}$ Carpenter, P., "Characterzation Strategies and Requirements for Lmar Regolith Simulan Materals", Lumar Regoth Simulant Materials Workshop, Huntsville, AL, 2005. 